\title{
Erratum to: Analyzing the dependences of multi- category purchases on interactions of marketing variables
}

\section{Harald Hruschka ${ }^{1}$}

\section{Erratum to: J Bus Econ}

\section{DOI 10.1007/s11573-016-0820-x}

In the original publication of the article, Eq. (4) was incorrectly published. The operation + was inadvertently published as - in the original version. The correct equation is given below:

$$
\begin{aligned}
& A I C=-2 L L+2 n_{p} \\
& B I C=-2 L L+\ln (I) n_{p}
\end{aligned}
$$

The online version of the original article can be found under doi:10.1007/s11573-016-0820-x.

Harald Hruschka

harald.hruschka@wiwi.uni-regensburg.de

$1 \quad$ University of Regensburg, 93040 Regensburg, Germany 